Original Article

\title{
The effect of modified cervical exercise on smartphone users with forward head posture
}

\author{
Yong- Soo Kong, PhD, $\mathrm{PT}^{1)}$, Yu- Mi Kim, PhD, PT ${ }^{2)}$, Je-Myung Shim, PhD, $\mathrm{PT}^{2)^{*}}$ \\ 1) Department of Physical Therapy, Gangneung Yeongdong College, Republic of Korea \\ 2) Department of Physical Therapy, College of Health and Science, Kangwon National University: \\ 346 Hwangjo-ri, Dogye-eup, Samcheok-si, Kangwon-do 245-905, Republic of Korea
}

\begin{abstract}
Purpose] The purpose of this study was to evaluate the effect of modified cervical exercise and determine whether such exercise improves the range of motion of the cervical movement in smartphone users with forward head posture. [Subjects and Methods] Some 32 subjects with forward head posture participated in this study. They were randomly allocated to three groups, and the modified cervical exercises were performed either once, twice, or three times per day. The exercise program was followed for four weeks and then the joint range of motion of the participants was measured. [Results] A significantly increased range of motion was seen in all three groups that performed the modified cervical exercises. The analysis of the effects among the three groups indicated that the greatest effect was seen in Group C, members of which performed the modified exercises three times per day. In addition, a significant difference was found between Group A and Group C in terms of the inter-group results. [Conclusion] According to the results of this study, although the modified cervical exercises were performed for only a relatively short duration (four weeks), the exercises brought about an improvement in the forward head posture that was induced by using a smartphone. Key words: Forward head posture, Cervical exercise, Smartphone
\end{abstract}

(This article was submitted Oct. 4, 2016, and was accepted Nov. 11, 2016)

\section{INTRODUCTION}

For many people in today's society, a smartphone is one of life's essential goods. Some $56 \%$ of the population of the United States use a smart phone, and the average time spent on a smartphone per day is 5.1 hours ${ }^{1)}$. The number of mobile phone subscribers in Korea was approximately 57,330,000 in March 2015, 41,260,000 of whom were smartphone subscrib$\mathrm{ers}^{2}$. It is commonplace for smartphones to be used to access music, video, and social network services (SNS), as well as to make and receive calls. Smartphones have become not only an example of modern high-tech equipment, but also a daily necessity. If people have used a smartphone for a long time, their posture might appear slouched. Smartphones, unlike computers, feature a small screen that is likely to induce a more slouched posture toward a line of sight below eye level ${ }^{3)}$. When used for a long time, a video terminal such as a smartphone might therefore induce an improper posture, for example, forward head posture or slouched posture ${ }^{4)}$.

Forward head posture (FHP) is a common neck disease in contemporary society, and it is caused by sitting at a desk for a long time ${ }^{5)}$. Maintaining a continuous posture leads to damage to the ligaments around the neck or lumbar ${ }^{6}$. In addition, such a posture is caused by muscle fatigue and decreased physical activity. As a result, the weakness of the respiratory muscle decreases the lung capacity and increases pain and disease ${ }^{7)}$. Eventually, excessive use of a smartphone may cause the maintenance of a slouched head posture for a long time and hence impose stress on the musculature as well as skeletal changes that may cause the loss of the C-shaped curve in the cervical spine, which may start to curve forward instead. Such

*Corresponding author. Je-myung Shim (E-mail: sjm7896@hanmail.net)

(C2017 The Society of Physical Therapy Science. Published by IPEC Inc.

This is an open-access article distributed under the terms of the Creative Commons Attribution Non-Commercial No Derivatives (by-nc-nd) License $<$ http://creativecommons.org/licenses/by-nc-nd/4.0/>. 
a disarrangement may cause homeostasis, which controls the blood supply and metabolites in the muscles, and it can result in significant pain and a loss of function ${ }^{8)}$.

Forward head posture is defined as a posture that adopts upper cervical extension and lower cervical flexion. The center of gravity of the head in this posture is positioned at the front rather than the vertebral body weight ${ }^{9,10)}$. This increase in forward head posture has been demonstrated to correlate with respiratory muscle weakness in patients who have neck trouble, and it leads to muscle weakness and a decrease in the range of motion ${ }^{11,12}$. In addition, forward head posture usually leads to increased stress due to the muscle shortening of the neck extensors, especially at the back of the head ${ }^{13)}$. Thus, this problem can be addressed through an improvement of the forward head posture, for example, muscle strengthening for posture alignment or stretching for shortened muscles $\left.{ }^{14}, 15\right)$. In order to treat forward head posture, it is necessary to consider the correct posture, work environment, and exercise therapy ${ }^{16}$. In order to improve this posture, heat, traction, and exercise have all been used ${ }^{17)}$. Various methods such as joint mobilization, stretching, isometric strengthening exercises, endurance exercises, and proprioceptive exercises have also been applied depending on the method and theory utilized by the therapist or the patient's condition $^{18)}$. The exercises recommended by Mackenzie and Kendall have also been used to treat forward head posture ${ }^{19)}$.

McKenzie's exercise program involves repeated self-treatment exercises performed by patients, with a focus on extension exercises. The exercise program includes joint motion exercises, manual therapy, and patient education. Kendall's exercise program focuses on the notion that unstable forward head posture can be corrected via alignment exercises, although this not only involves strengthening the deep neck flexors and shoulder retractors, but also stretching the chest muscles ${ }^{20)}$. For participants with forward head posture, this study applied a modified cervical exercise that combined McKenzie's and Kendall's exercises, which have proven the effectiveness of exercise.

The aim of this study was to investigate the effect of the modified cervical exercise program and determine the importance of therapeutic exercise. The study also aimed to examine the impact of the exercise program on participants' joint range of motion.

\section{SUBJECTS AND METHODS}

The initial subjects chosen for this study were 39 adults (21 males and 18 females) recruited at Kangwon National University. However, those subjects with a craniovertebral angle (CVA) of more than $54^{\circ}$ were excluded. Therefore, 32 subjects (17 males and 15 females) ultimately participated in the study. Their mean age was $21.6 \pm 1.9$ years, their mean height 168.4 $\pm 8.8 \mathrm{~cm}$, and their average weight $65.0 \pm 12.0 \mathrm{~kg}$ (Table 1). The subjects understood the experimental purpose and methods and agreed voluntarily to participate in the study. The research participants also signed written informed consent forms in accordance with the Declaration of Helsinki before beginning the experiment.

The inclusion criteria for this study were the following: more than one year using a smartphone, a CVA of less than 54, no disabilities affecting dizziness or balance, no nervous system or musculoskeletal disease, and no respiratory problems. The following exclusion criteria were applied: vestibular system problems, and being unable to perform the exercises. The 32 selected subjects were randomly allocated to three groups that performed the modified exercises either once, twice, or three times per day for four weeks.

The modified cervical exercises were performed in the following manner: (1) slowly pull the subject's neck to the head, thereby attaching the chin to the neck; (2) the subject's eyes should be looking directly forward; (3) hold both hands on the back of the subject's head; (4) ask the subject to push his/her head backwards against the hands; and (5) ask for the hands to be spread as wide as possible in order to stretch the pectoralis major. Each group performed three sets of exercises, with one set being defined as five circuits, that is, performing $7 \mathrm{sec}$ of exercises followed by $10 \mathrm{sec}$ of rest. To reduce the potential for errors, skilled physical therapists supervised the performance of the exercises. Group A performed the exercises in the morning, Group B exercised in the morning and afternoon, while Group C exercised in the morning, afternoon, and the evening. The modified cervical exercises were performed five times per week for four weeks.

The craniovertebral angle is defined as the angle between a horizontal line passing through the $\mathrm{C} 7$ vertebra and a line extending from the tragus of the ear to the $\mathrm{C} 7$ vertebra. With their head in a natural resting position, the subjects were asked to focus on a target that was positioned at eye level. While taking a picture of the lateral view in order to measure the angle correctly, the tragus of the ear was marked and a pointer was taped to the skin overlying the spinous process of the C7 vertebra. Foot scanner (Gaitview Pro 1.0, alFOOTS, South Korea) was used to measure the CVA. The subjects were photographed

Table 1. General characteristics of subjects $(\mathrm{N}=32)$

\begin{tabular}{lccc}
\hline & $\begin{array}{c}\text { Group A } \\
(\mathrm{n}=11)\end{array}$ & $\begin{array}{c}\text { Group B } \\
(\mathrm{n}=11)\end{array}$ & $\begin{array}{c}\text { Group C } \\
(\mathrm{n}=10)\end{array}$ \\
\hline Age (years) & $20.9 \pm 1.7$ & $21.4 \pm 1.5$ & $22.5 \pm 2.2$ \\
Weight $(\mathrm{kg})$ & $60.0 \pm 10.4$ & $68.3 \pm 12.7$ & $66.9 \pm 12.0$ \\
Height $(\mathrm{cm})$ & $166.5 \pm 7.6$ & $170.1 \pm 10.6$ & $168.7 \pm 8.5$ \\
\hline
\end{tabular}

Values are means \pm standard deviation. 
using the posture analyzing system among the functions of the foot scanner and then the photos were analyzed by cross-line of posture test. To reduce the errors in this study, the average value was calculated from three measurements. All statistical analyses were performed using SPSS version 18. A paired t-test was used to determine the difference in the CVA pre- and post-exercise. A one-way ANOVA was used to determine the inter-group differences. In addition, the Bonferroni post-hoc test was used. The statistical significant level was set as $\mathrm{p}<0.05$.

\section{RESULTS}

A significantly increased range of motion was seen in all three groups that performed the modified cervical exercises $(p<0.05)$. According to the analysis of the effects among the three groups, the greatest effect was seen in Group C, members of which performed the modified exercises three times per day. In addition, the post-hoc analysis indicated that there was a significant difference between Group A and Group C ( $<<0.05)$ (Table 2).

\section{DISCUSSION}

Although smartphones have similar functions to devices such as computers and televisions, as well as offering functions related to music, utilizing the small screen on a smartphone makes it difficult to maintain a proper posture. The normal spinal curvature is not maintained because of the forward head posture adopted when using a computer or smartphone for a long time. As a result, smartphone users experience an increase in musculoskeletal problems in the neck and shoulder ${ }^{21)}$. Therefore, the importance of exercise and proper training should be emphasized for people who are likely to develop postural deformities due to incorrect posture habits and daily living patterns. The purpose of this study was to investigate how the degree of momentum of the modified cervical exercise affects participants in terms of improving their forward head posture.

For the improvement of forward head posture, this study offered modified cervical exercises that were a combination of the movements recommended by Mackenzie and Kendall. The exercises were performed five days a week for four weeks. In addition, the participants were randomly allocated to three groups depending on the amount of exercise sessions performed per day: once a day, twice a day, or three times a day.

The results of this study showed that there were significant differences among the three groups pre- and post-training. The forward head posture showed the most improvement $\left(8.76 \pm 5.06^{\circ}\right)$ in the group that exercised three times a day, followed by the group that exercised twice a day $\left(5.71 \pm 4.42^{\circ}\right)$ and then the group that exercised once a day $\left(3.88 \pm 3.42^{\circ}\right)$. The mean of the participants' CVA was increased from $50.62 \pm 4.56$ to $56.67 \pm 4.83$, and it showed improved ROM in the cervical spine. The average angle of the participants' CVA was found to increase the range of motion of the joints in the cervical spine. The significant difference in all groups after pre-post training was able to mean that the modified cervical exercise was effective to improve forward head posture. Although the group A that performed the modified cervical exercise one time per day was improved the CVA, the group $\mathrm{C}$ that performed the exercise three times per day showed more improvement. This means that the more exercise a subject do, the better the subject's head posture is. Harman ${ }^{22}$ demonstrated the effect of Kendall's exercise program in a study involving a treatment group and a control group with forward head posture. The results of this study were consistent with those of that prior study.

The modified cervical exercises in this study consisted of neck extension exercises and stretching of the chest muscles at the same time. In addition, the participants pulled their chins to the back of the head and then the cervical deep muscles of the neck were strengthened with pressure posteriorly. Further, the chest muscles were stretched as much as possible by holding the hands beyond the head. This posture not only stretches the chest muscles, but also strengthens the scapular retractor muscles. The modified cervical exercises only took 8 minutes. Although they only required a short time to complete, the exercises appeared to be effective in improving forward head posture. In addition, the modified head exercises proved effective in increasing the range of motion of those with forward head posture when performed three times a day.

The modified cervical exercises were simple and easy-to-follow exercises. Additionally, the exercises lead to an improvement for subjects who have forward head posture and who do not have enough time to dedicate to other exercises likely to improve their posture. The modified cervical exercises attempted in this study were found to be effective in improving the

Table 2. Comparison of forward head posture among groups (Unit: angle)

\begin{tabular}{llll}
\hline & Pre & \multicolumn{1}{c}{ Post } & Change \\
\hline Group A & $50.9 \pm 3.2$ & $54.8 \pm 5.1^{* *}$ & $3.8 \pm 3.4^{3^{*}}$ \\
Group B & $51.7 \pm 5.1$ & $57.4 \pm 4.2^{* *}$ & $5.7 \pm 4.4$ \\
Group C & $49.0 \pm 5.1$ & $57.8 \pm 4.8^{* * *}$ & $8.7 \pm 5.0^{1^{*}}$ \\
\hline${ }^{*} \mathrm{p}<0.05, * * \mathrm{p}<0.01, * * * \mathrm{p}<0.001$ & \\
1 significantly different compared with group a & \\
2 Significantly different compared with group b & \\
${ }^{3}$ Significantly different compared with group C &
\end{tabular}


movement of forward head posture. Therefore, the modified cervical exercises combining Mackenzie's exercise program and Kendall's exercise program, which were known to effectively decrease neck pain and increase ROM, are considered to contribute to the recovery and improvement of forward head posture. In addition, it is suggested that the modified cervical exercises are able to prevent chronic diseases in people with forward head posture but other symptoms.

This study did have some limitations, for example, the small sample size and the lack of control over participants' activities, leading to problems with generalization. Future studies should therefore consider the number of subjects and the persistency of the improved posture following the intervention.

\section{REFERENCES}

1) Pew Research Center: Smartphone Ownership 2013 [Internet]. Washington D.C. (Accessed Jun. 5, 2013)

2) Ministry of Science, ICT and Future Planning. Subscriber statistics of wired and wireless communication services. 2015, Republic of Korea.

3) Greig AM, Straker LM, Briggs AM: Cervical erector spinae and upper trapezius muscle activity in children using different information technologies. Phy Ther, 2005, 91: 119-126.

4) Janwantanakul P, Sitthipornvorakul E, Paksaichol A: Risk factors for the onset of nonspecific low back pain in office workers: a systematic review of prospective cohort studies. J Manipulative Physiol Ther, 2012, 35: 568-577. [Medline] [CrossRef]

5) Good M, Stiller C, Zauszniewski JA, et al.: Sensation and distress of pain scales: reliability, validity, and sensitivity. J Nurs Meas, 2001, 9: 219-238. [Medline]

6) Bonney RA, Corlett EN: Head posture and loading of the cervical spine. Appl Ergon, 2002, 33: 415-417. [Medline] [CrossRef]

7) Okuro RT, Morcillo AM, Ribeiro MÂ, et al.: Mouth breathing and forward head posture: effects on respiratory biomechanics and exercise capacity in children. J Bras Pneumol, 2011, 37: 471-479. [Medline] [CrossRef]

8) Visser B, van Dieën JH: Pathophysiology of upper extremity muscle disorders. J Electromyogr Kinesiol, 2006, 16: 1-16. [Medline] [CrossRef]

9) Gonzalez HE, Manns A: Forward head posture: its structural and functional influence on the stomatognathic system, a conceptual study. Cranio, 1996, 14: 71-80. [Medline] [CrossRef]

10) Griegel-Morris $\mathrm{P}$, Larson K, Mueller-Klaus K, et al.: Incidence of common postural abnormalities in the cervical, shoulder, and thoracic regions and their association with pain in two age groups of healthy subjects. Phys Ther, 1992, 72: 425-431. [Medline]

11) Kapreli E, Vourazanis E, Strimpakos N: Neck pain causes respiratory dysfunction. Med Hypotheses, 2008, 70: 1009-1013. [Medline] [CrossRef]

12) Kapreli E, Vourazanis E, Billis E, et al.: Respiratory dysfunction in chronic neck pain patients. A pilot study. Cephalalgia, 2009, 29: 701-710. [Medline] [CrossRef]

13) Kebaetse M, McClure P, Pratt NA: Thoracic position effect on shoulder range of motion, strength, and three-dimensional scapular kinematics. Arch Phys Med Rehabil, 1999, 80: 945-950. [Medline] [CrossRef]

14) Janda V: Muscle and motor control in cervicogenic disorders. In: Physical therapy of the cervical and thoracic spine. Edinburgh: Churchill Livingstone, 1994, pp 195-216.

15) Kendall fP, McCreary EK, Provance PG, et al.: Muscles testing and function with posture and pain, 5th ed. Lippincott Williams \& Winkins, 2005.

16) Neumann DA: Kinesiology of the musculoskeletal system: foundations for rehabilitation Elsevier Health Sciences, 2013.

17) Posner J, Glew C: Neck pain. Ann Intern Med, 2002, 136: 758-759. [Medline] [CrossRef]

18) Sarig-Bahat H: Evidence for exercise therapy in mechanical neck disorders. Man Ther, 2003, 8: 10-20. [Medline] [CrossRef]

19) McKenzie R: Treat your own neck. Raumati Beach: Spinal Publications, 1983.

20) Kendall FP, Elizabeth KM, Patricia GP: Muscles: testing and function. Baltimore: Williams \& Wilkins, 1993.

21) Berolo S, Wells RP, Amick BC 3rd: Musculoskeletal symptoms among mobile hand-held device users and their relationship to device use: a preliminary study in a Canadian university population. Appl Ergon, 2011, 42: 371-378. [Medline] [CrossRef]

22) Harman K, Hubley-Kozey CL, Butler H: Effectiveness of an exercise program to improve forward head posture in normal adults: a randomized, controlled 10-week trial. J Manipulative Physiol Ther, 2005, 13: 163-176. [CrossRef] 